Article

\title{
Vibration Analyses of a Gantry Structure by Mobile Phone Digital Image Correlation and Interferometric Radar ${ }^{\dagger}$
}

\author{
Francesco Mugnai $^{1, *(D)}$, Antonio Cosentino ${ }^{2}\left(\mathbb{D}\right.$, Paolo Mazzanti $^{2,3}{ }^{\mathbb{D}}$ and Grazia Tucci $^{1}(\mathbb{D})$ \\ 1 Department of Civil and Environmental Engineering, University of Florence, Via di Santa Marta 3, \\ 50139 Firenze, Italy; grazia.tucci@unifi.it \\ 2 Department of Earth Sciences, University of Rome "Sapienza", P. le Aldo Moro 5, 00185 Rome, Italy; \\ antonio.cosentino@uniroma1.it (A.C.); paolo.mazzanti@uniroma1.it (P.M.) \\ 3 NHAZCA S.r.1., Start-Up University of Rome "Sapienza", Via V. Bachelet n.12, 00185 Rome, Italy \\ * Correspondence: francesco.mugnai@unifi.it \\ + This paper is an extended version of our conference paper: Mugnai, F.; Tucci, G.; Da Re, A. Digital Image \\ Correlation in Assessing Structured-Light 3D Scanner's Gantry Stability: Performing David's (Michelangelo) \\ High-Accuracy 3D Survey. Int. Arch. Photogramm. Remote. Sens. Spat. Inf. Sci. 2021, 46, 463-469.
}

Citation: Mugnai, F.; Cosentino, A.; Mazzanti, P.; Tucci, G. Vibration Analyses of a Gantry Structure by Mobile Phone Digital Image Correlation and Interferometric Radar. Geomatics 2022, 2, 17-35. https://doi.org/10.3390/ geomatics2010002

Academic Editor: Bruce D. Chapman

Received: 9 December 2021

Accepted: 24 December 2021

Published: 27 December 2021

Publisher's Note: MDPI stays neutral with regard to jurisdictional claims in published maps and institutional affiliations.

Copyright: (C) 2021 by the authors. Licensee MDPI, Basel, Switzerland. This article is an open access article distributed under the terms and conditions of the Creative Commons Attribution (CC BY) license (https:// creativecommons.org/licenses/by/ $4.0 /)$.
Abstract: The study presents results from applying the Real Aperture Radar interferometry technique and Digital Image Correlation through a mobile phone camera to identify static and dynamic deformations of a gantry during surveying operations on the Michelangelo's David at the Galleria dell'Accademia di Firenze Museum in Florence. The statue has considerable size and reaches an elevation of more than seven meters on its pedestal. An ad-hoc gantry was designed and deployed, given the cramped operating area around the statue. The scanner had a stability control system that forbid surveying in instrument movements. However, considering the unicity of the survey and its rare occurrence, the previous survey had been carried out in the year 2000; verifying stability and recording deformations is a crucial task, and necessary for validation. As the gantry does not have an on-board stability sensor, and considering the hi-survey accuracy requested, a redundant, contactless, remote monitoring system of the gantry and the statue stability was chosen to guarantee the maximum freedom of movement around the David to avoid any interference during scanning operations. Thanks to the TInRAR technique, the gantry and the statue were monitored with an accuracy of $0.01 \mathrm{~mm}$. At the same time, a Digital Image Correlation analysis was performed on the gantry, which can be considered a Multi-Degree-Of-Freedom (MDOF) system, to accurately calculate the vibration frequency and amplitude. A comparison between TInRAR and DIC results reported substantial accordance in detecting gantry's oscillating frequencies; a predominant oscillation frequency of $1.33 \mathrm{~Hz}$ was identified on the gantry structure by TinSAR and DIC analysis.

Keywords: TInRAR; Digital Image Correlation; RARAD interferometry

\section{Introduction}

Structural monitoring systems are widely adopted to estimate the behavior of structures under ambient and forced vibrations in a laboratory or field environment and used to monitor structures under other excitations, such as earthquakes, traffic, gusts, or live loads. Standard monitoring techniques usually involve sensors that require full contact (e.g., accelerometers) [1]. In recent decades, innovative technical solutions for the comprehensive and accurate characterization of the dynamic properties of structures have increased rapidly [2-5]. Remote sensing technologies have been developed mainly for applications of periodic monitoring and the control of the state of conservation of the structures [6], known in the scientific literature as "Structural Health Monitoring" (SHM) [7-11]. One of the most effective remote sensing techniques for SHM is Terrestrial Radar Interferometry (TInRAR) [12,13], which is increasingly used for the rapid assessment of specific 
structural characteristics (such as vibration frequencies, modal forms, oscillation amplitudes, and damping factors) and whose effectiveness is fully proven [2]. From the various studies [12,14] it was observed that this TInRAR remote sensing technique for SHM applications could provide results comparable to those obtained through other conventional 'contact' monitoring techniques, such as velocimeter or accelerometer, or sensor networks installed on structures [2,15-17]. Following Schumacher and Shariati [18], which used the Virtual Visual Sensor (VVS) method to accurately calculate the fundamental vibration frequency of s's DOF (single-degree-of-freedom), it is possible to extend the analysis to multi-degree-of-freedom (MDOF) and continuous systems as the gantry is [19]. In this case study, a dynamic analysis of a metal structure was carried out using the TInRAR technique, which has seen many applications in the literature, but combined with a new application of Digital Image Correlation (DIC) [20] through PhotoMonitoring ${ }^{\text {TM }}$ techniques [21,22]. At the beginning of the 2000s, image processing methods and techniques were designed and their effectiveness were improved in parallel with algorithms, computing power, and sensors [23-25]. Digital image processing can be considered one of the most innovative branches among remote sensing techniques and can identify and detect a structure's surface changes [26,27]. The basic concept is that small changes in the intensity value of a monitored pixel with fixed coordinates caused by the vibration of structures can be captured by employing techniques, such as the Fast Fourier Transform (FFT) [18]. In this approach, as first suggested by Patsias and Staszewskiy [27,28], each pixel of a digital video or photo taken on a structure can represent a candidate virtual visual sensor (VVS) that can be used for SHM purposes.

Thanks to high-quality performances and contactless features, some authors have used ground-based optical and video cameras for structural monitoring purposes [29-31]. Some algorithms and software, e.g., IRIS developed by NHAZCA, have been designed and produced for PhotoMonitoring applications. The proposed methodology involves using the FFT to reveal the fundamental frequency of vibration of a pixel by observing the variation of its intensity over time within a series of digital images [18]. The measurement of displacements achievable with the DIC analysis technique depends on the sensor type. Camera type, size, quality and resolution of the sensor, photographic lens, and the distance between the camera and the scenario being monitored are crucial variables. In the application field, the DIC technique allows for monitoring, in a spatially continuous and automatic way, of the sectors of the scenario characterized by deformation processes. The rate and trend of displacement can be provide a quantitative estimate [22]. The DIC analyses were conducted on the IRIS software, taking full advantage of the multi-master analysis module, which analyses a stack of images. Every single dataset image can be used as a master and a slave in different and consecutive correlation cycles. Therefore, it is possible to correlate the $n-1$ slave images with the $n$ master images, generating at each cycle for the $n$ available images, $\mathrm{n}-1$ correlation maps, thus obtaining the advantages of reducing environmental noise, increasing accuracy, and allowing long-term analysis [31] (Figure 1).

For this case study, frames were extracted from the video recorded simultaneously as the TInRAR acquisition and a multi-master analysis were performed, analysing up to $30 \mathrm{~s}$ of frames (i.e., 1800 images). 


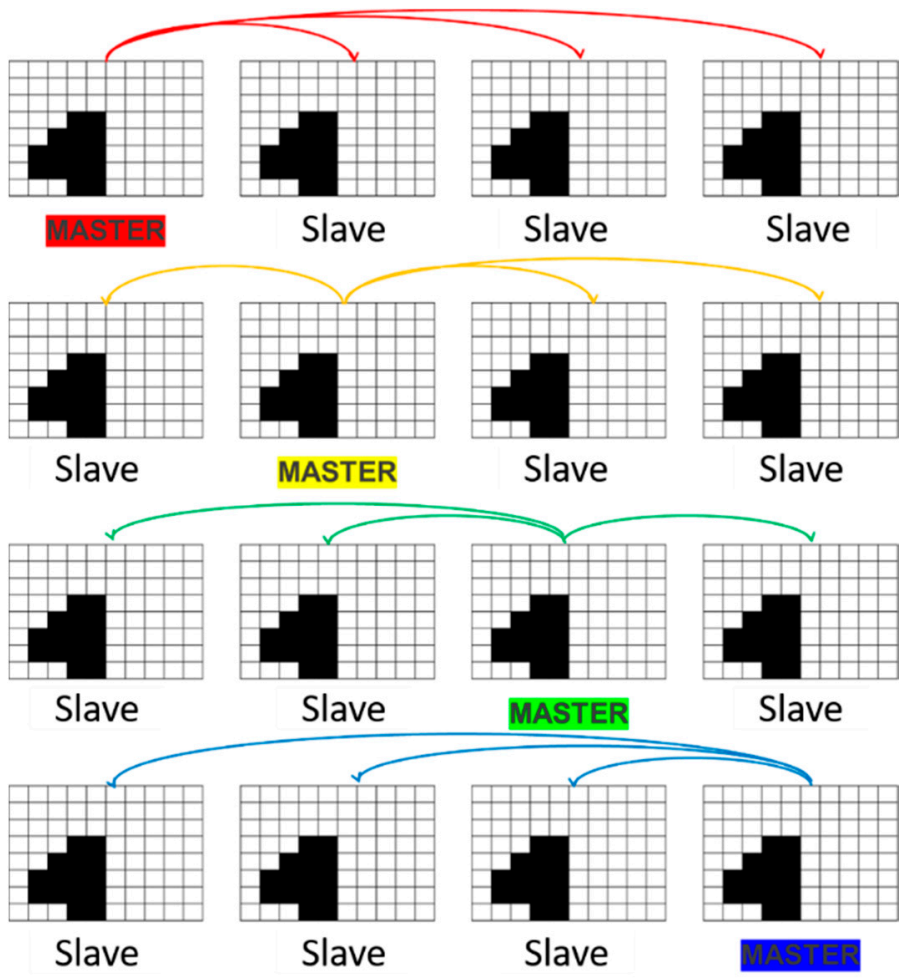

Figure 1. Progressive correlation scheme used to achieve the fully redundant stack of correlation maps (Multimaster Analysis) [31].

\section{Test Site}

Michelangelo Buonarroti's David is one of the most famous masterpieces worldwide. It is universally recognised as the icon of the Florentine Renaissance. David has been chosen to represent Italy at the Expo 2020 Dubai, thanks to his significance and cultural heritage value. The Ministry of Cultural Heritage and Tourism as well as the Italian Commissariat for Expo 2020 Dubai commissioned the twin of the masterpiece. The development of accurate and cost affordable 3D surveying techniques and instruments have in recent years permitted to extend the use of the most cutting-edge technologies and methods to architectural, environmental, and cultural heritage fields. Some studies [32-35] and surveys [36-38] were carried out on David's statue for various purposes. In this case, the 3D survey was performed using a structured-light 3D scanner from Hexagon Manufacturing Intelligence: the StereoScan neo (Hexagon Manufacturing Intelligence, 2020). The instrument was developed for automotive industries. Considering his performances and technical specs, such as accuracy in the order of microns, he was exploited to create David's digital twin1. The obtained 3D model was then used to realise a real-size 3D print of the statue. In 1998, a Stanford University and Washington University jointed research team, headed by Prof. Marc Levoy, carried out a scanning campaign of the statue with a resolution of $0.29 \mathrm{~mm}$ and a dynamic range of 20,000:1 [32,33].

\subsection{The Venue}

The Michelangelo's David is hosted in the Galleria dell'Accademia. The Galleria's history began in 1563 and occupied the present venue in 1882. The David was moved from Piazza Della Signoria to the Galleria in August 1873, and it is hosted by the Tribune designed by architect Emilio De Fabris to host it. The statue rises in the middle of the so-called La Tribuna room (Figures 2 and 3). Three La Tribuna room sides are open and link the room with two other huge rooms as well as a smaller one. 


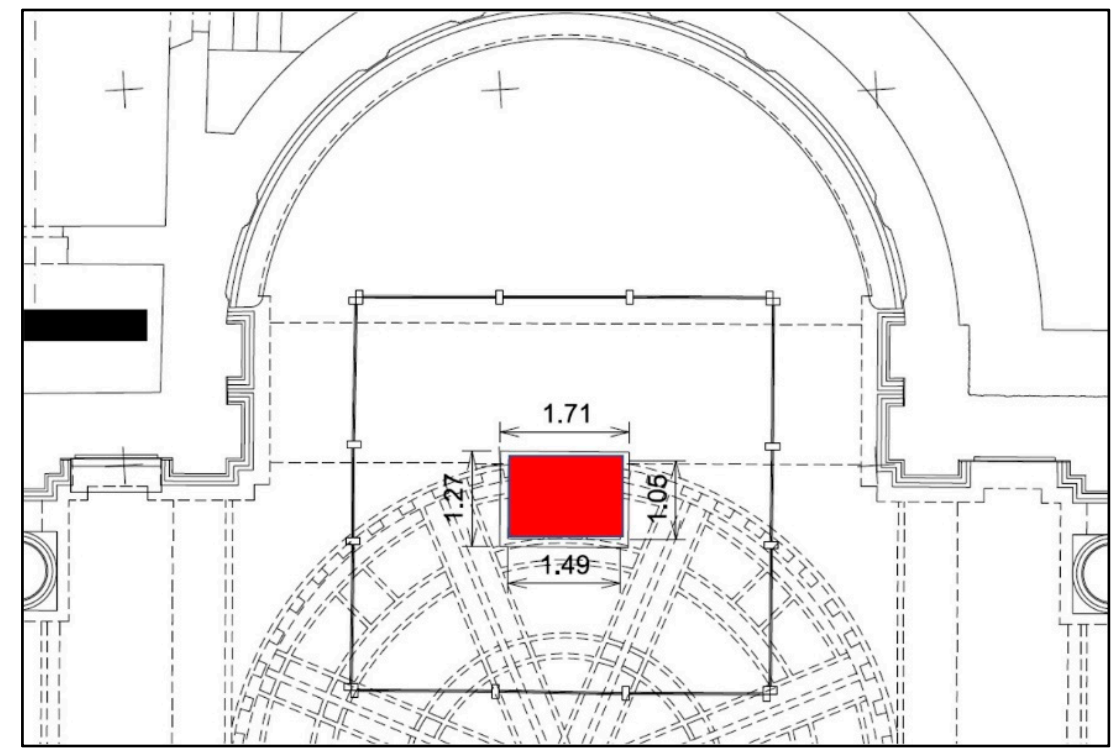

Figure 2. Top view map of the exhibition area in the Galleria dell'Accademia. In red is David's pedestal. Quotes are in metres.

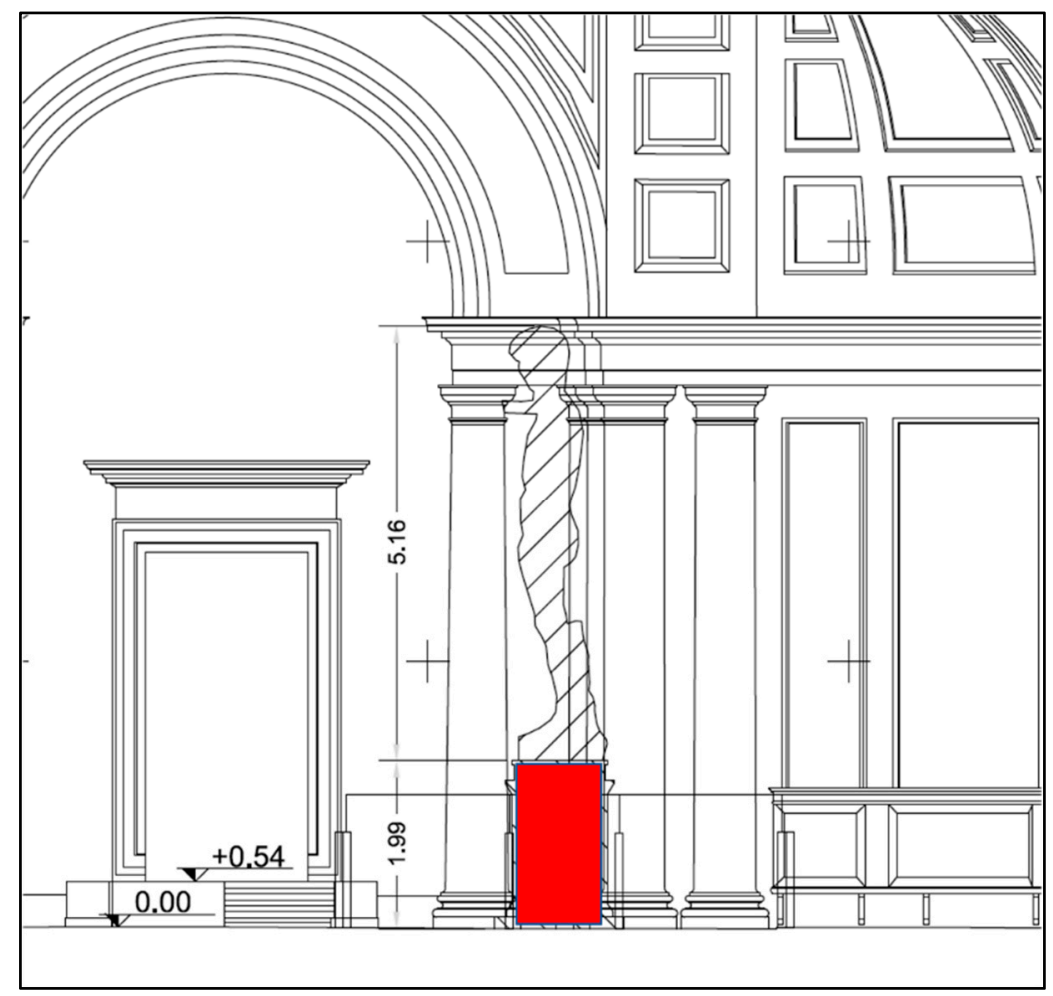

Figure 3. Lateral view map of the David statue on its pedestal within the Galleria dell'Accademia in Florence. In red is David's pedestal. Quotes are in metres.

The last side of the room has a rounded shape. The ceiling is composed of a dome.

\subsection{The Statue}

The statue has been sculpted from a single piece of marble and is of considerable size high (Table 1). 
Table 1. David's characteristics.

\begin{tabular}{cc}
\hline Total Surface & $19.47 \mathrm{~m}^{2}$ \\
Volume & $2098 \mathrm{~m}^{3}$ \\
Weight & $5.57 \mathrm{tons}$ \\
Height without pedestal & $5.16 \mathrm{~m}$ \\
\hline
\end{tabular}

It is hosted on a pedestal that is $1.99 \mathrm{~m}$ high. A low glass fence rounds the statue during the conventional exhibition period to keep visitors far from the statue itself. However, the fence was temporarily removed to facilitate surveying and monitoring campaigns; although the gantry was designed and sized to be freely moved within the fenced area, the risk of direct contact with the masterpiece and the risk of unexpected damage forced for fence removal.

\subsection{The Gantry}

The gantry in Figure 4 is mainly composed of alloy and iron, comprises of a platform, a central body that can be lifted or lowered thanks to a manual hydraulic actuator, and support for anchor cameras, scanners, or other sensors on the top.

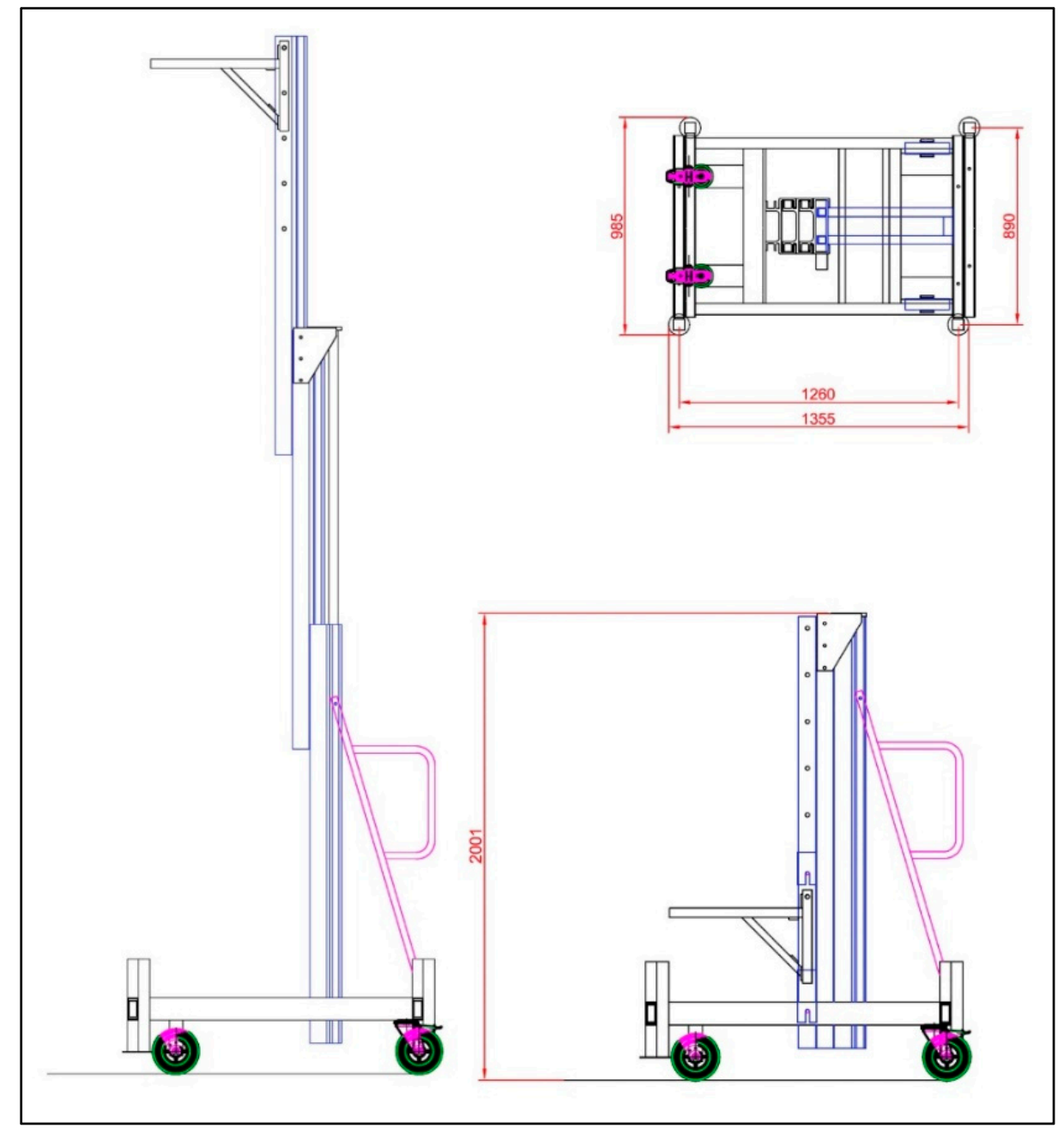

Figure 4. Gantry's scheme and sizes.

The four wheels and the extendible arms (Figure 5) allow for easily moving the gantry around David's pedestal and stable measurement positions. 


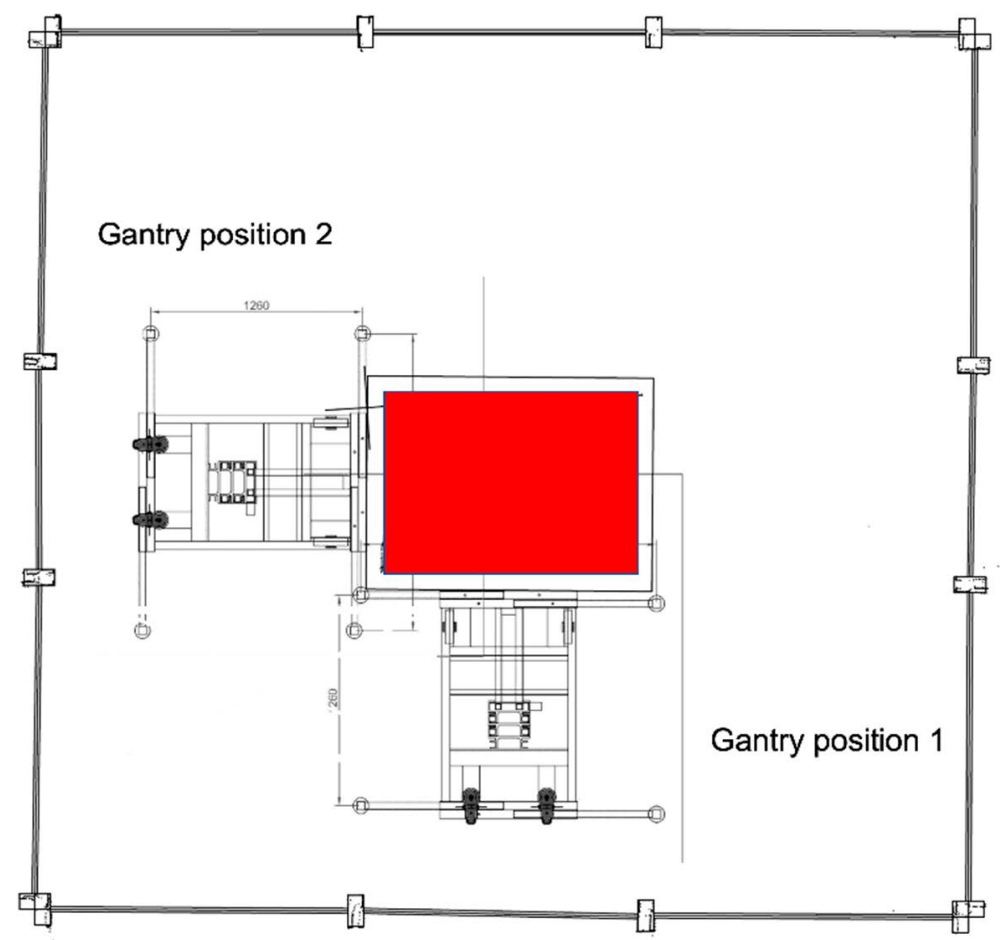

Figure 5. Top view map of the David's surrounding the area with two examples of scanning positions.

\section{Materials and Methods}

\section{1. $T I n R A R$}

According to the meaning of its acronym radar, Radio Detection and Ranging, a radar device can detect and range objects. The radar acquires echoes from the different targets in its antenna field of view (FOV) [38]. The interferometric technique allows the calculation of displacements along the instrument-scenario line of sight (LOS) by comparing the phase information of the emitted and reflected electromagnetic wave at different time intervals [22]. Real aperture ground-based radar (TInRAR) is a remote sensing technique, through which simultaneously measuring displacements of numerous points of buildings, structures, or other anthropogenic and natural elements is possible. Furthermore, thanks to high data sampling frequencies, enabling both static and dynamic analyses (vibration measurement) can be carried out at the same time [22].

TInRAR techniques to assess the vibration state of structures, such as bridges, have been well established since the early 2000s [34,35]. Several papers have been published on the monitoring of bridges, wind turbine towers [36-38], buildings [39], and towers [40]. In recent years, several research groups have suggested the development of new systems [38].

The acquisitions were carried out by a radar device marketed by IDS Georadar S.r.1. with interferometric capabilities: the IBIS-FS. The RAR device is comprised of a sensor module, a control PC, a power supply unit, and data processing software (Figure 6).

The sensor module transmits an electromagnetic signal at a central frequency of 17.2 $\mathrm{GHz}$ (Ku band) with a maximum bandwidth of $200 \mathrm{MHz}$ and an accuracy of up to $0.1 \mathrm{~mm}$. The main characteristics of the sensor are shown in Table 2

Table 2. Main IBIS radar characteristics.

\begin{tabular}{ccccccc}
\hline Parameter & $\begin{array}{c}\text { Operating } \\
\text { Frequency }\end{array}$ & $\begin{array}{c}\text { Max. } \\
\text { Operational } \\
\text { Distance }\end{array}$ & $\begin{array}{c}\text { Max. Range } \\
\text { Resolution }\end{array}$ & $\begin{array}{c}\text { Nominal } \\
\text { Displacement } \\
\text { Accuracy }\end{array}$ & $\begin{array}{c}\text { Max. } \\
\text { Acquisition } \\
\text { Rate }\end{array}$ & $\begin{array}{c}\text { Weight/Battery } \\
\text { Autonomy }\end{array}$ \\
\hline Value & $\begin{array}{c}17.2 \mathrm{GHz} \\
(\mathrm{Ku} b a n d)\end{array}$ & $1000 \mathrm{~m}$ & $0.75 \mathrm{~m}$ & $10^{-5} \mathrm{~m}$ & $200 \mathrm{~Hz}$ & $12 \mathrm{~kg} / 5 \mathrm{~h}$ \\
\hline
\end{tabular}




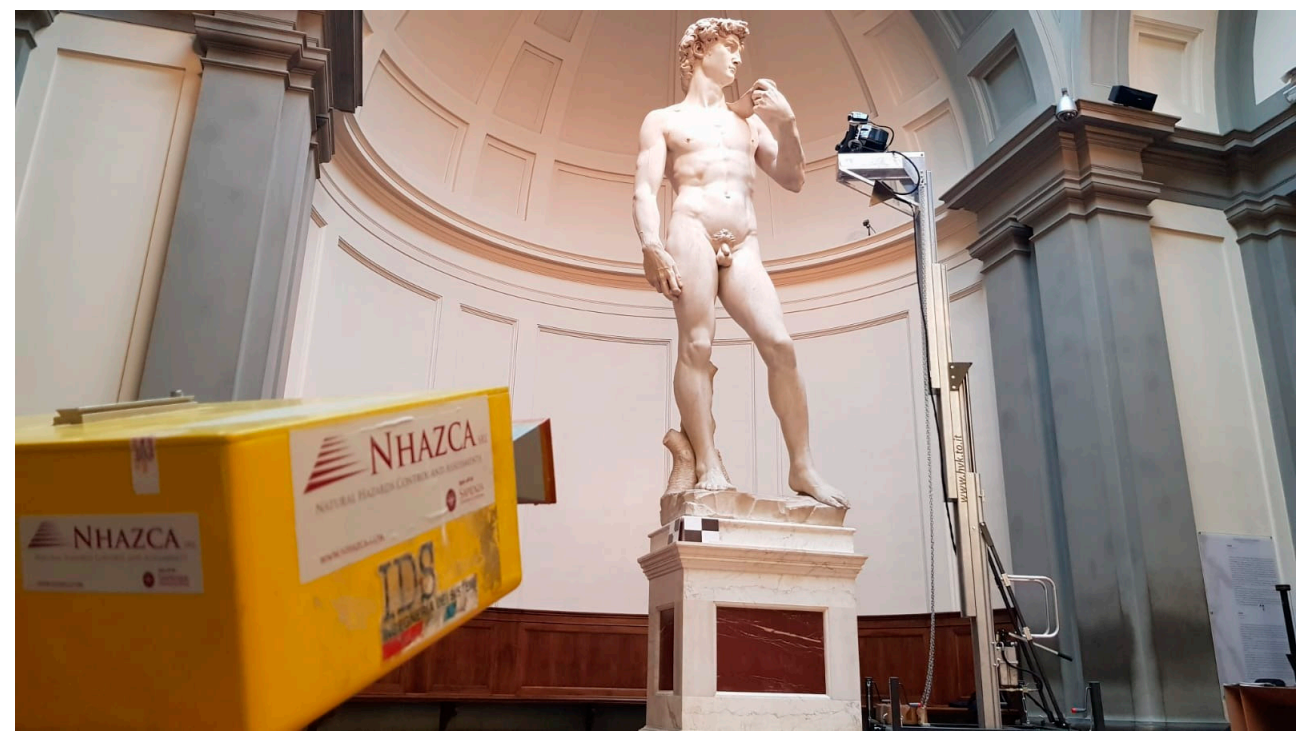

Figure 6. IBIS radar looks toward David and the gantry. The scanner is on top of the gantry.

\subsection{Photomonitoring}

PhotoMonitoring is a monitoring solution that exploits the widespread use of opti$\mathrm{cal} /$ multispectral sensors to obtain information about changes or displacements in the scene observed, making it an ideal tool for studying and monitoring surface deformation processes in the context of land and structure control. Photomonitoring is based on the concept of "digital image processing", i.e., the manipulation of digital images to obtain data and information. Analyses can be carried out on datasets of images acquired from the same type of platform, on the same area of interest, at different times, and can be conducted using specific algorithms that allow the evaluation of any variation in radiometric characteristics (Change Detection) and the displacement occurred in the time interval covered by the acquisition of images (Digital Image Correlation). Different digital approaches can be used to analyze and manipulate available images, and different types of information can be extracted depending on the type of image processing chosen, as shown by [41]. Digital image processing techniques are based on extracting information about changes in the terrain by comparing different types of images (e.g., satellite, aerial, or terrestrial images) collected at different times over the same area and scene [42].

DIC (Digital Image Correlation) is an optical-numerical measurement technique capable of providing full-field 2D surface displacements or deformations of any object. Digital Image Correlation (DIC) allows quantitatively evaluating the displacement and deformations between two images acquired at different times by analyzing the different pixel blocks and obtaining a resolution that can increase up to 1/100th of a pixel, as shown in Figure 7 [42]. According to [43], automatic matching and correlation algorithms can theoretically provide a sub-pixel accuracy of about $1 / 50$ th of a pixel, although problems such as image orientation, co-registration, topographic distortion, instrumental and atmospheric noise, temporal and spatial decorrelations, and co-registration errors are still limitations; therefore, higher resolution input data are needed [42].

DIC analysis was performed using IRIS software, developed by NHAZCA S.r.l., startup of "Sapienza", University of Rome. By analyzing the data acquired from different platforms and sensors, the software allows for Change Detection (CD) and Digital Image Correlation (DIC). The IRIS software allows Digital Image Correlation (DIC) analyses to be carried out using different algorithms. In this case, the analysis was carried out using the Phase Correlation (PC) algorithm [44], which is based on a frequency domain representation of the data, usually calculated through fast Fourier transforms, with a floating window (Figure 8). 


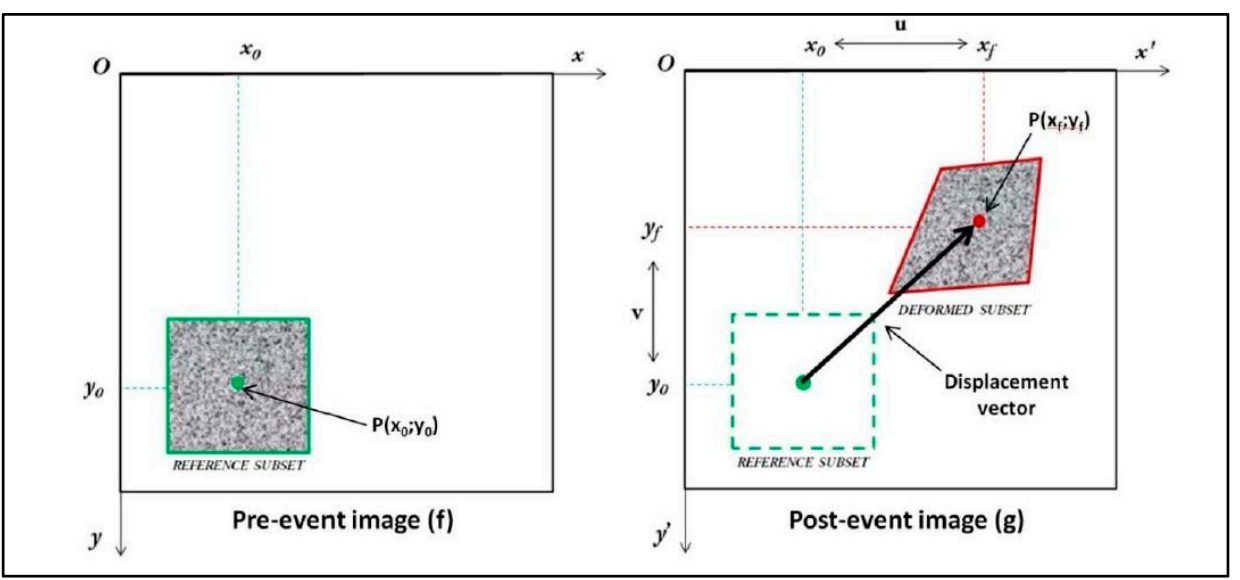

Figure 7. Schematic diagram of the basic principle of DIC [42].

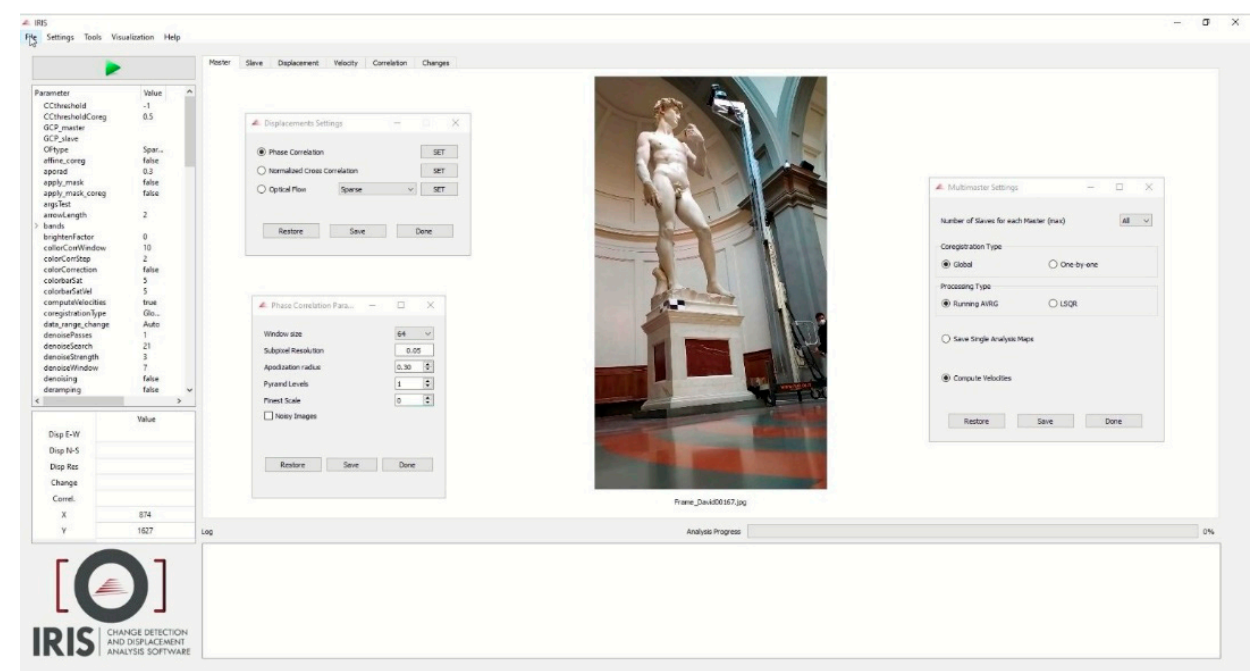

Figure 8. Preview of the IRIS Software by NHAZCA S.r.l.

The video footage was taken using a Redmi Note 8T smartphone with the features shown in Table 3.

Table 3. Redmi Note 8T camera features [45].

\begin{tabular}{cc}
\hline Sensor & $48.0 \mathrm{MP}$ \\
Sensor Size & $1 / 2^{\prime \prime}$ \\
FOV & $79.4^{\circ}$ \\
Video Resolution & Full HD 1080p \\
FPS Video & $60 \mathrm{FPS}$ \\
Aperture & $\mathrm{f} / 1.75$ \\
Pixel size & $0.8 \mu \mathrm{m}$ \\
\hline
\end{tabular}

The camera, which is fixed on a sturdy and stable tripod, was positioned to record the compound displacements in the gantry's $x, y, z$ axes and the statue of David.

\subsection{TInRAR and DIC Surveys}

The reported acquisitions with the TInRAR system and camera were performed with the forklift at the maximum lift (Figure 9). 


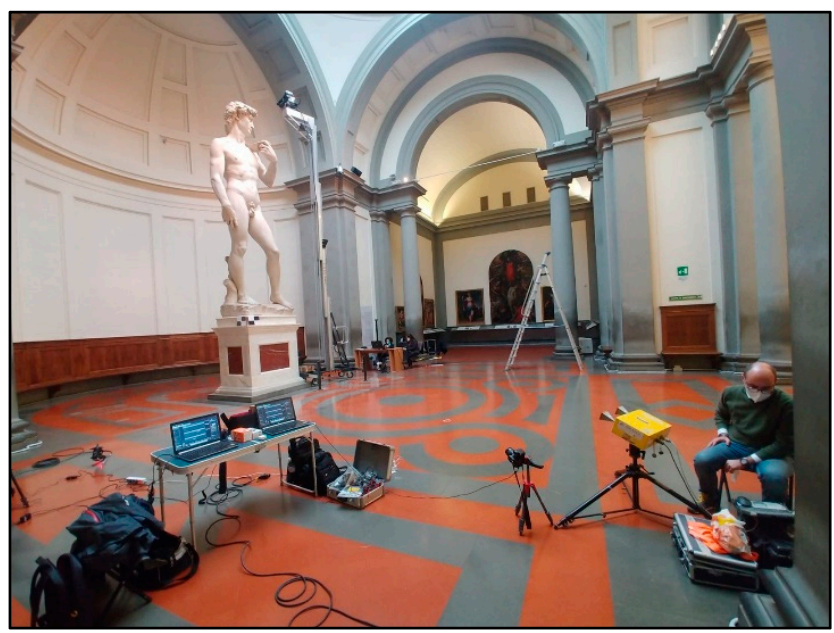

Figure 9. View the instrumentation set-up and arrangement within the La Tribuna room.

The measuring systems were positioned at $45^{\circ}$ from the gantry longitudinal side and at a distance of approximately $11 \mathrm{~m}$ (Figure 10).

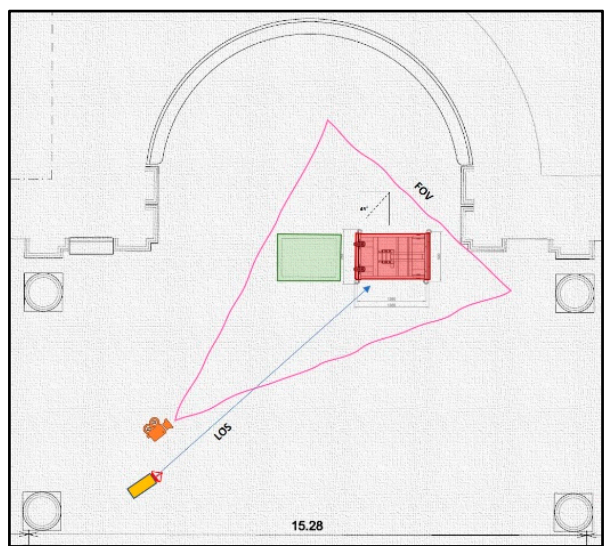

(a)

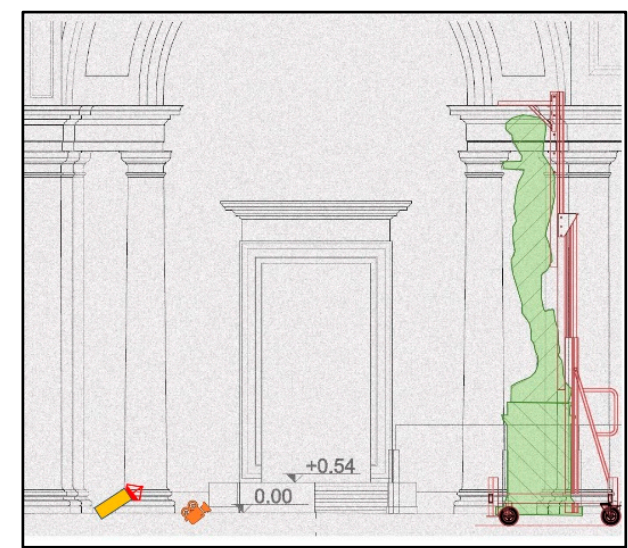

(b)

Figure 10. (a) Top view map of the study area with camera and radar positions (David in green and gantry in red) that shows the field of view (FOV) of the optical sensor and the line of sight (LOS) of the radar sensor; (b) Frontal map of the study area with camera and radar positions, (in green the David and in red the gantry).

The optical sensor installed on a tripod recorded 1080p video at $60 \mathrm{fps}(60 \mathrm{~Hz})$, progressive video at 60 frames per second, and a resolution of $1920 \times 1080$ pixels. The Ground Sampling Distance (GSD), i.e., the size of a pixel on the structure, is approximately $5 \mathrm{~mm}$.

The radar instrument was mounted on a sturdy tripod equipped with a rotating head to adjust the orientation of the sensor towards the structure under investigation. The location and dimension of the measured radar bins are defined by the FOV of the transmitting and receiving antennas and the range resolution. The bins that correspond to the highest signal peaks are usually selected to analyze their displacement time series [46]. A control PC manages the sensor unit through standard USB communication, which is provided with system management software to configure the acquisition parameters, store the measured data, and show the displacements in real-time (Figure 11). 


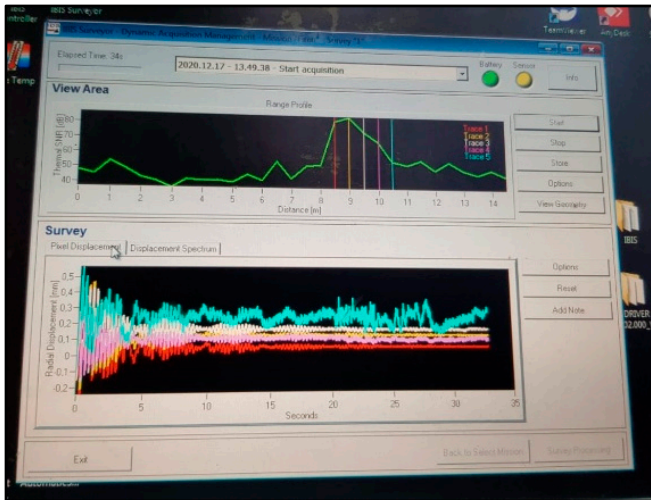

(a)

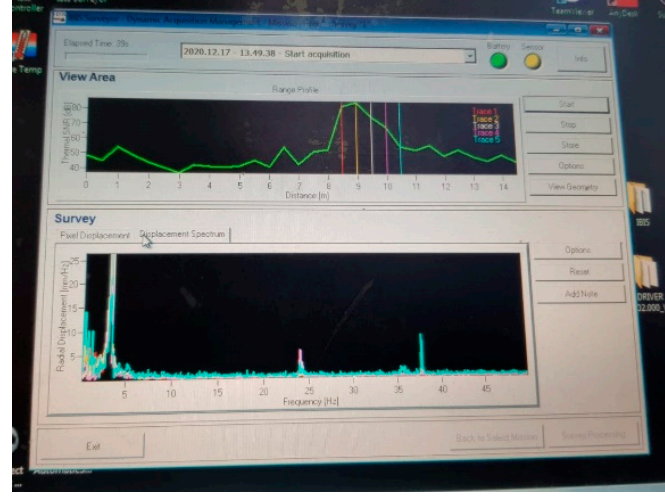

(b)

Figure 11. (a) Screenshot showing the bins corresponding to the highest peaks of the received signal identified and selected to show the displacement time series in real-time from the control PC; (b) Screenshot of the control PC returning the frequency analysis for the selected bins with highest peaks in real-time.

With the IBIS-S radar, the acquisitions were made at a frequency of $100 \mathrm{~Hz}$, i.e., 100 data per second, setting a maximum range resolution of $0.75 \mathrm{~m}$ to obtain the most significant possible number of measurement points on the structure (Figure 12).

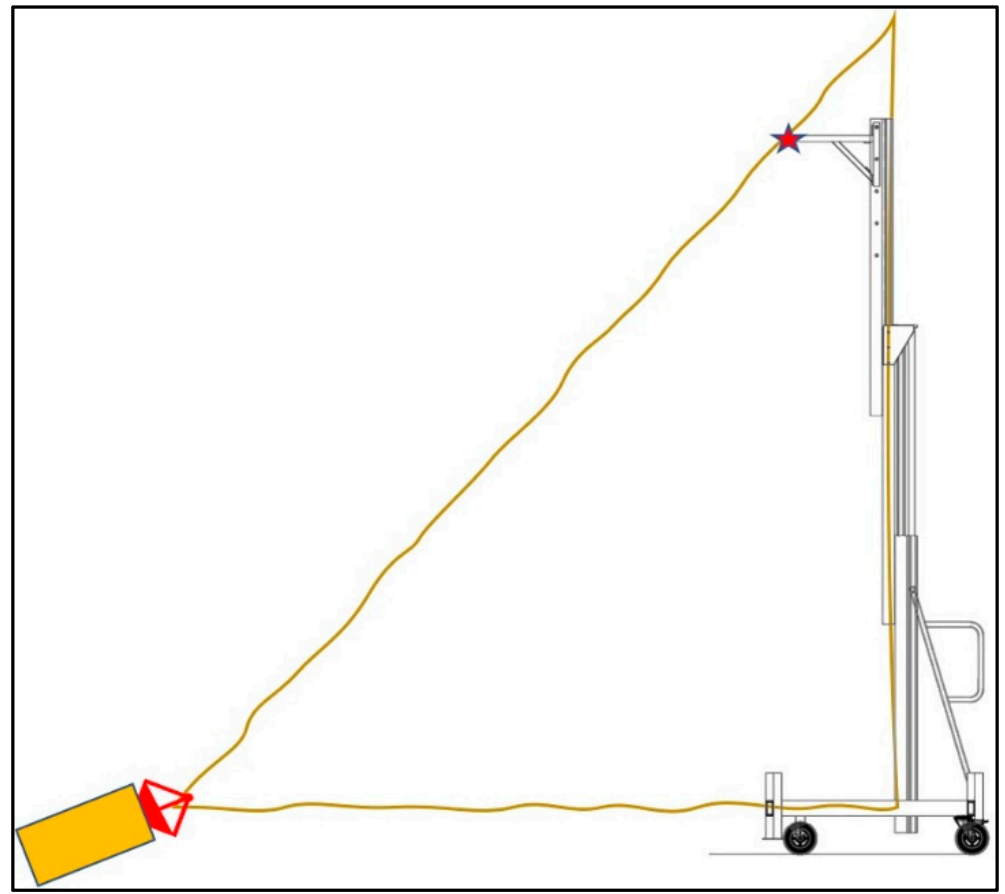

Figure 12. Simplified diagram of the measurement of displacements along the line of sight (LOS). The measurements reported in the paper correspond to the star position.

With the positioning adopted, i.e., with the instruments close together, it was possible to combine the radar's ability to make measurements along the LOS with the optical sensor's ability to make displacement measurements in the plane perpendicular to that of the line of sight, thus monitoring three different components of displacement (Figure 13). 


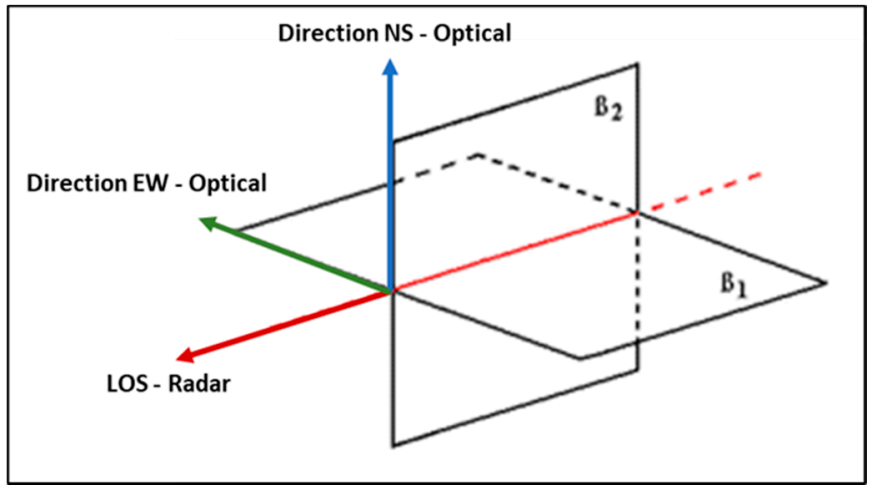

Figure 13. View of David from the camera position.

\section{Results}

This section presents some of the obtained results performing TInRAR and Digital Image Correlation analysis and comparison. During the acquisition campaigns, the gantry was moved several times to cover the 294 different scan positions. However, the very peculiar venue and the incommensurable David's value put time and space constrictions on the study. For this reason, the acquisition by TInRAR and camera were carried out from a single position only. In particular, the TInRAR and camera were put very close with a minimal Line of Sight dealignment $\left(<3^{\circ}\right)$.

\subsection{DIC Analysis}

DIC analyses were performed by processing images through the IRIS software (Figure 14). In this paper, the cheek and top part of the gantry were analysed.

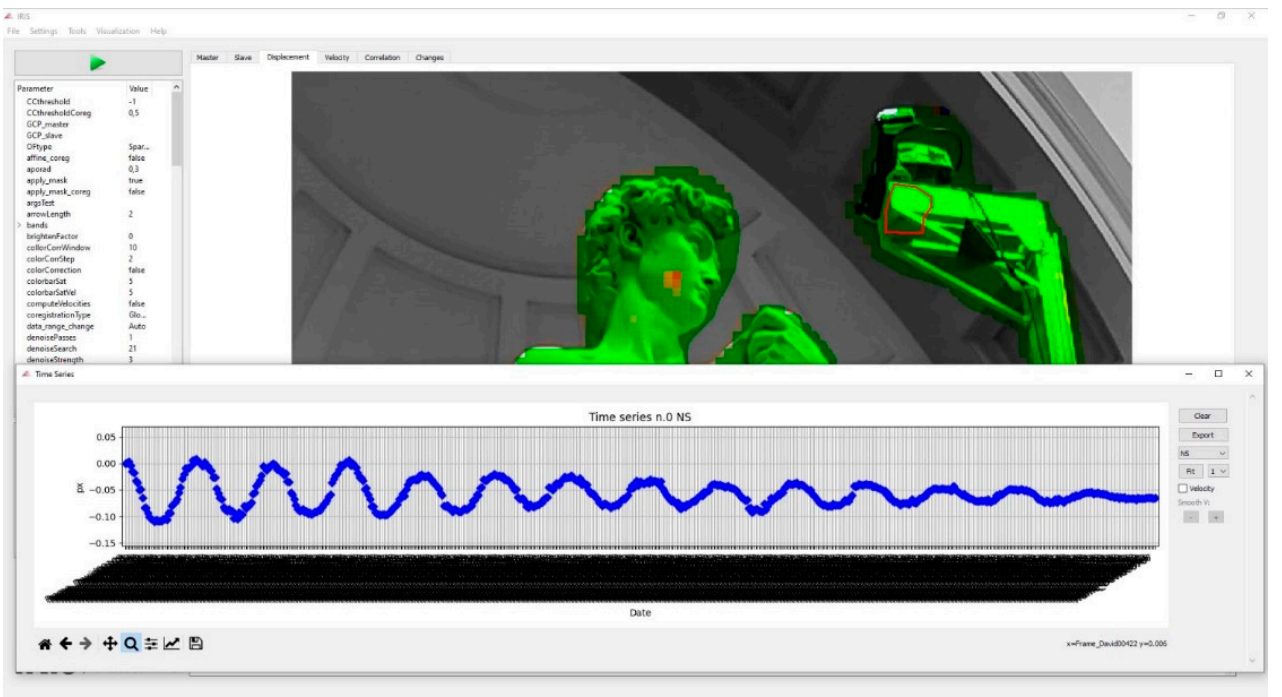

Figure 14. Superimposition of DIC analysis's results on the 2D picture of David statue.

Figure 15 shows the chart of the DIC analysis' outcomes. The maximum amplitude of the east-west (horizontal) signal was 0.22 pixels $(\approx 1 \mathrm{~mm})$. The amplitude of the north-south (vertical) signal was 0.10 pixels $(\approx 0.5 \mathrm{~mm})$. N-S and E-W refer to the pictures vertical and horizontal axis, respectively. 


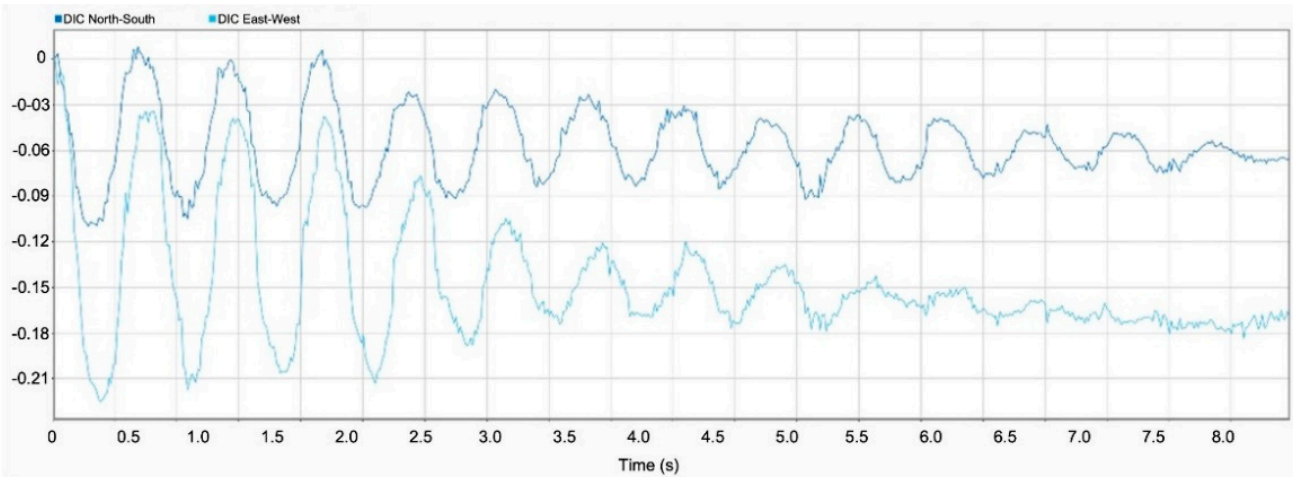

Figure 15. Signals comparison: DIC east-west direction (light blue); DIC north-south direction (dark blue); time (x-axis); amplitude expressed in pixels (y-axis).

\subsection{TInRAR}

Figures 16 and 17 show deformation charts of the TInRAR signal during the acquisition campaign on the gantry and the statue's cheek. The signal recorded on the statue does not contain any predominant frequency and maintains an amplitude value between 0.1 and $-0.2 \mathrm{~mm}$.

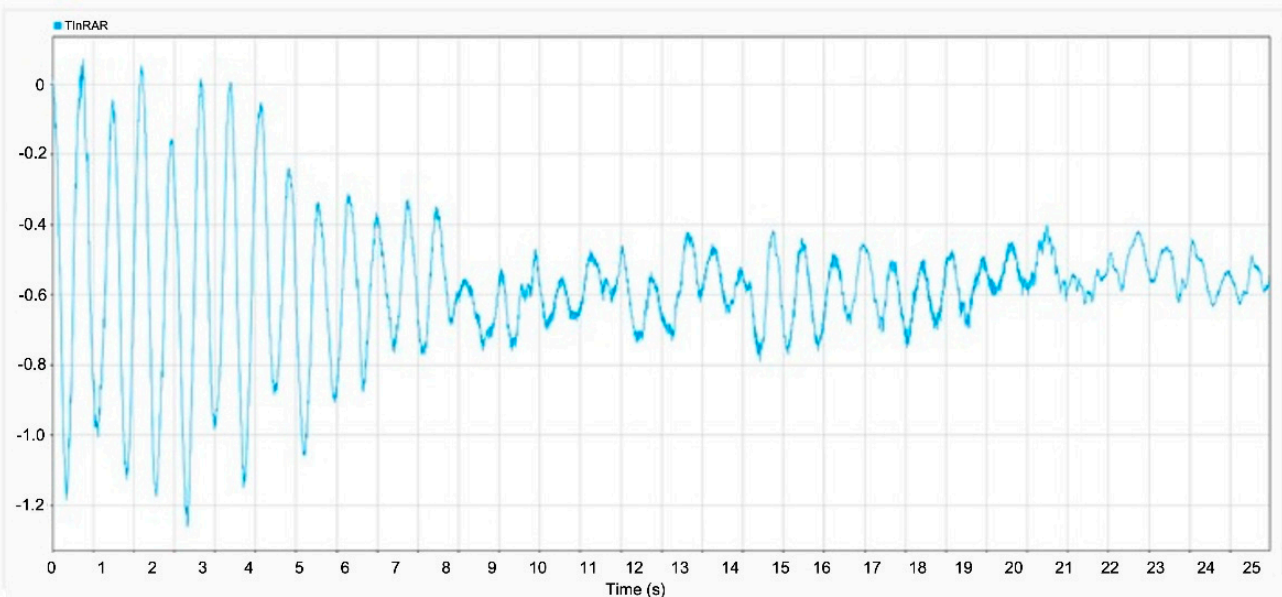

Figure 16. TInRAR signal. Time is expressed in seconds (x-axis), and amplitude is expressed in $\mathrm{mm}$ (y-axis).

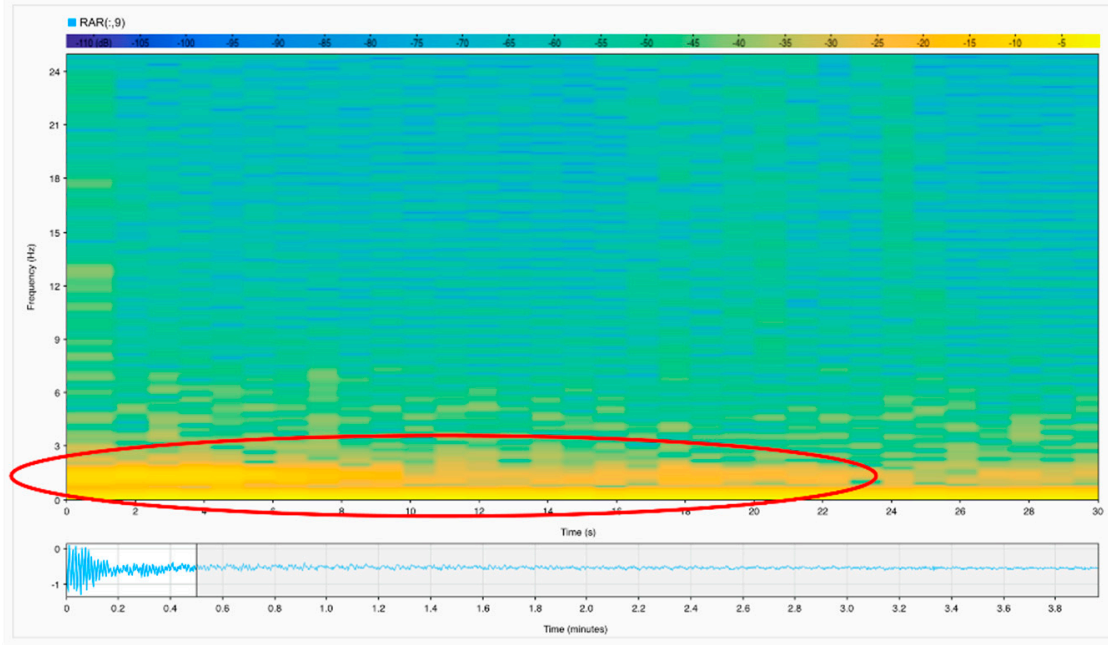

Figure 17. RAR signal spectrogram; $1.33 \mathrm{~Hz}$ frequency in the red ellipsis. 
By plotting results in the frequency domain and visualizing through a spectrogram (Figure 18), a frequency between 1 and $2 \mathrm{~Hz}$ can be identified in the lower-left area of the chart. The frequency is visible for the first $6 \mathrm{~s}$; it gradually diminishes until a nonperceivable value after $25 \mathrm{~s}$.

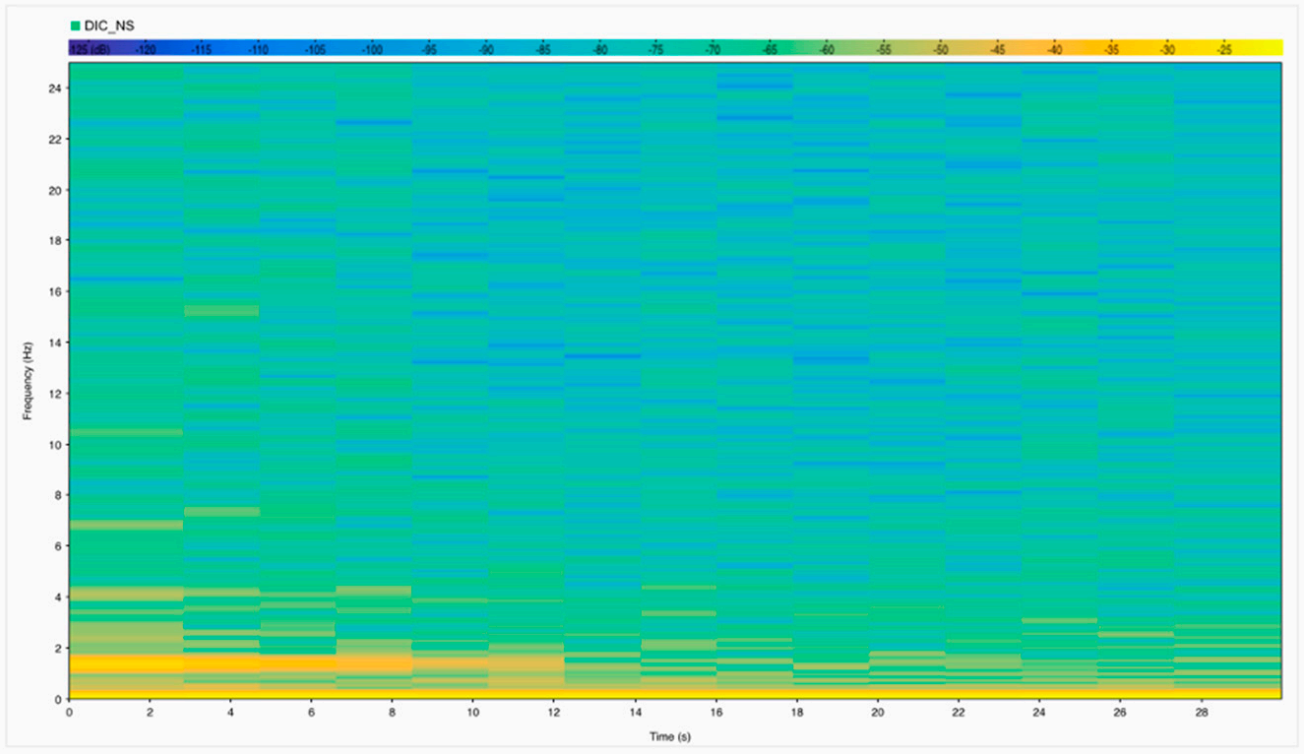

Figure 18. Spectrogram of the DIC north-south signal.

The frequency is noticeable by plotting DIC analysis both in the north-south direction (Figure 19) and in the south-east direction (Figure 20).

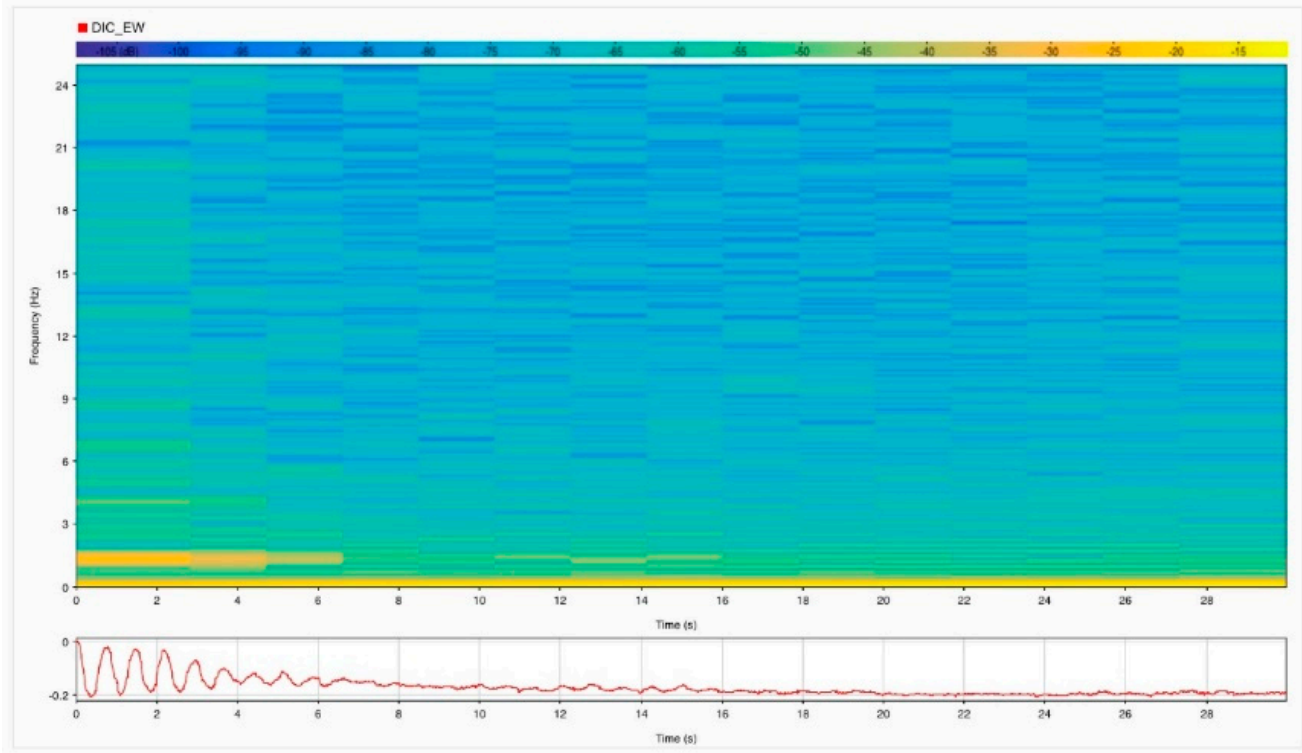

Figure 19. Spectrogram of the DIC east-west signal.

Figure 20 shows the DIC (red line) signal and TInRAR (blue line) signals in the frequency domain. The detected frequency is estimated from both monitoring systems as $1.33 \mathrm{~Hz}$. 


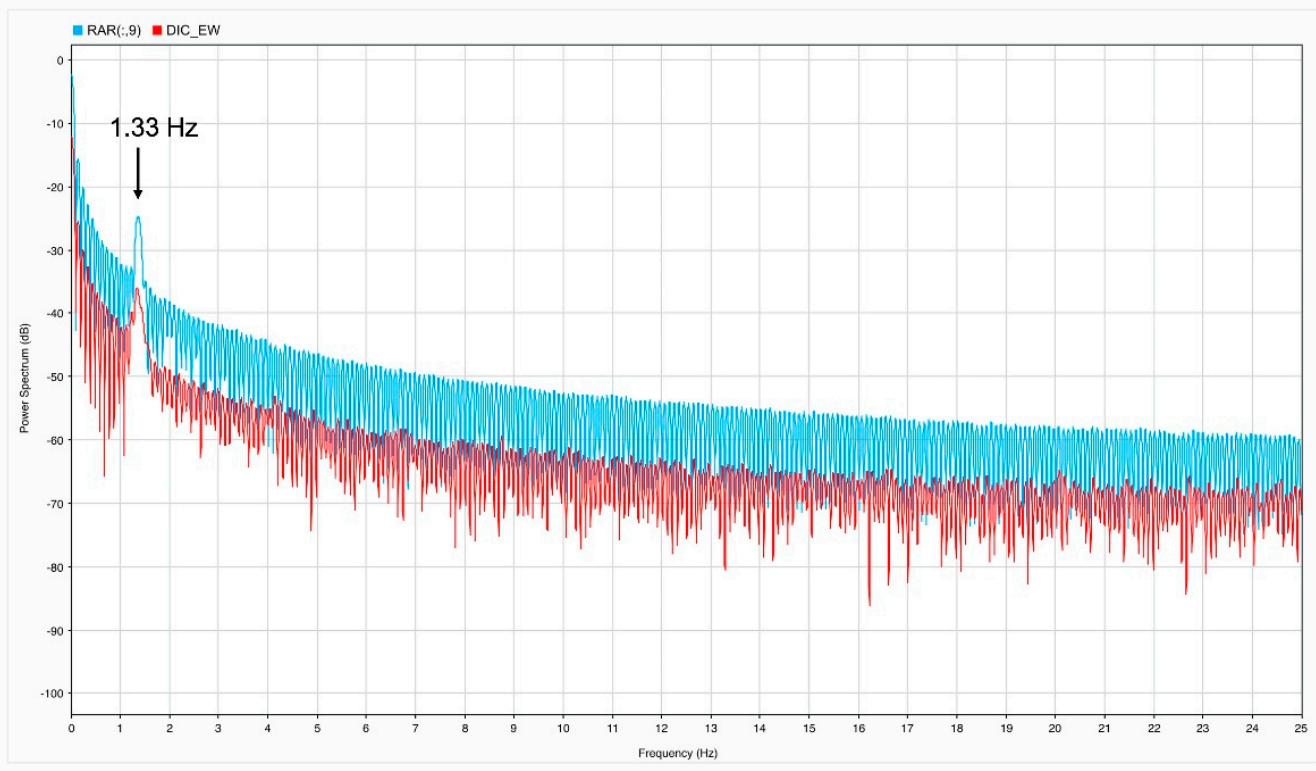

Figure 20. Signal comparison: RAR and DIC spectrum.

\section{Discussion}

The two different monitoring techniques, TInRAR and PhotoMonitoring, have produced comparable results measuring the same gantry structure. Both the signals showed a $1.33 \mathrm{~Hz}$ predominant oscillating frequency; the amplitudes witnessed comparable recorded displacements. The maximum measured displacement was 0.22 pixels $(\approx 1.2 \mathrm{~mm})$ from the DIC analysis, considering an analysis accuracy of up to $1 / 50$ th of a pixel, as reported by [43] under optimal environmental conditions. From TInRAR monitoring, a maximum displacement of $1.3 \mathrm{~mm}$ was detected. The subtle discrepancy can be explained by the different geometry of the measuring directions. The TInRAR measures along the direction of the line of sight, while the DIC analysis provides displacement measurements in a plane perpendicular to the line of sight. In this case, the north-south and east-west directions were studied. An angle of $\approx 45^{\circ}$ between the longest gantry side and the LOS of both TInRAR and optical sensor. A perfect alignment between TInRAR and the camera could not be achieved, as the camera body and tripod may have generated some interference on the radar measurement. However, a mismatch of less than $4^{\circ}$ could be considered insignificant; below this angle, the measurements could still be the line of sight that was obtained during the gantry direction monitoring. The 0.1-pixel difference between the north-south and the east-west component was partly due to the design of the gantry structure, which had an asymmetrical response to the stresses induced by the manual hydraulic elevation system and was partly related to a geometric and perspective component of the optical system related to the overall viewpoint.

As mentioned above, the acquisition campaign for DIC analysis was conducted, maintaining a constant frame rate of 60 frames per second on the camera settings. This resulted in a minimum time step of $0.016 \mathrm{~s}$. Each chart comprised a time span of $30 \mathrm{~s}$. The duration was decided in order to assume a substantial disposition of the gantry to stable behavior. The gantry's chart (Figure 11) showed that the line's trend after frame 500 could be interpreted as substantial stability [22]. After an initial perturbating pulse generated by the movement for increasing or decreasing gantry's elevation (the moving system was a manual pneumatic actuator), which imposed an oscillating movement to the gantry's body. In the chart in Figure 15, as well as the other charts, this was appreciable as a saw-teeth shape. However, the oscillation had a constant frequency of $1.33 \mathrm{~Hz}$ frames $(0.76 \mathrm{~s})$. From [22], the rigid body scanner was solidly fixed to the gantry's scanner support and showed the same behavior. 
A different situation could be seen by looking at Figure 21, showing the measurements on David's cheek, which shows a displacement of 0.03 pixels $(0.1 \mathrm{~mm})$, a value close to the error brought by the DIC analysis [43].

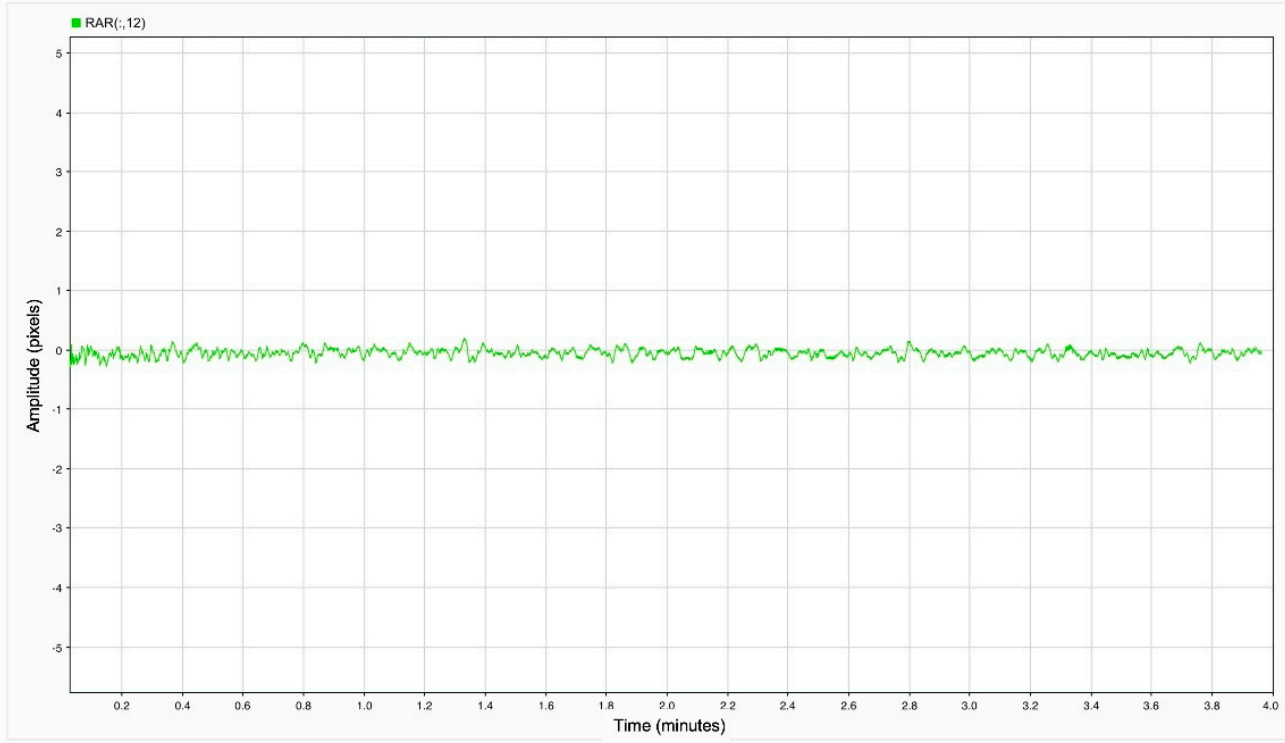

Figure 21. Amplitude chart of the TInRAR signal measured on the statue cheek.

Unlike the behavior recorded for the gantry's scanner support, the oscillation amplitude was smaller of one order of magnitude. Figure 22 shows that from DIC analysis carried out on the statue, the $1.33 \mathrm{~Hz}$ frequency is not present, and no other predominant frequencies were detected.

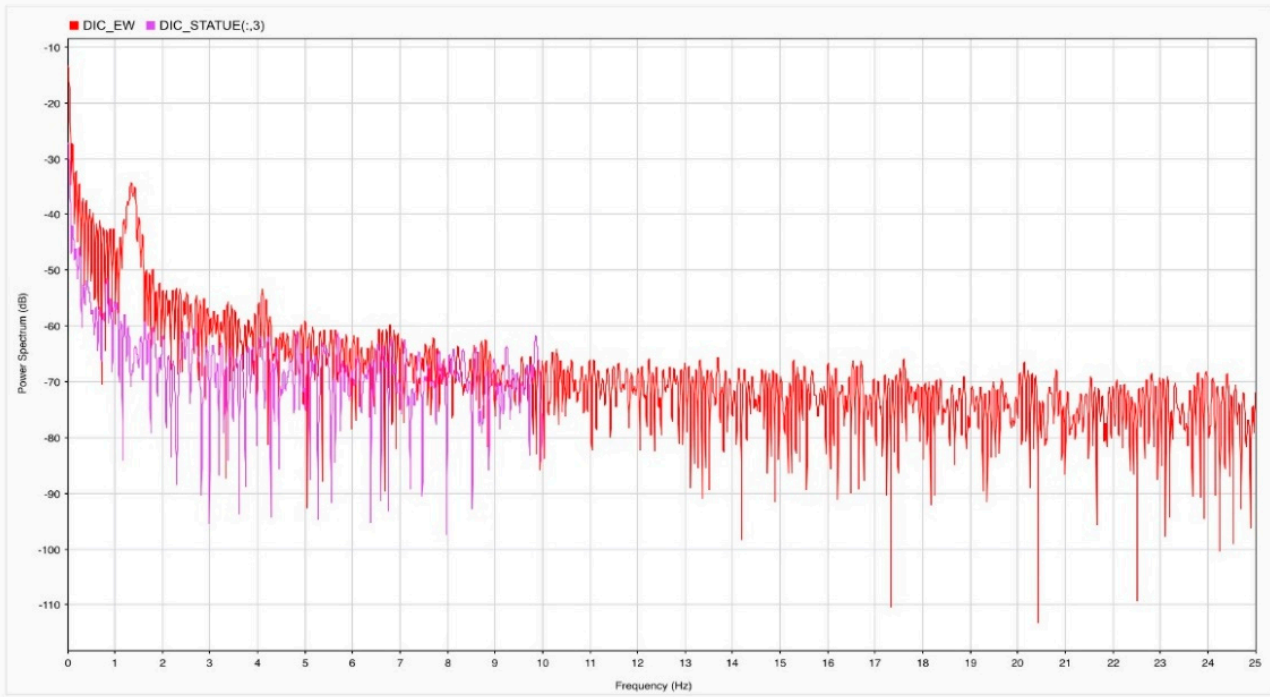

Figure 22. Comparison DIC analysis on the gantry (red) and the statue (light purple) [22].

A step further than Schumacher and Shariati [20] was completed in this work. In particular, a Virtual Visual Sensor (VVS) method was used, not only to accurately calculate the fundamental vibration frequency of s's DOF (single-degree-of-freedom), but also as a multidegree-of-freedom (MDOF) and continuous systems as the gantry is [19]. Furthermore, frequency and amplitude of vibration were given. It is worth mentioning that integrating results from monitoring using TInRAR technique and PhotoMonitoring allows for characterizing displacement on three perpendicular axes: the direction of the LOS for TIn- 
RAR, and two dimensions on the perpendicular plane to the LOS of the PhotoMonitoring sensor (Figure 23).

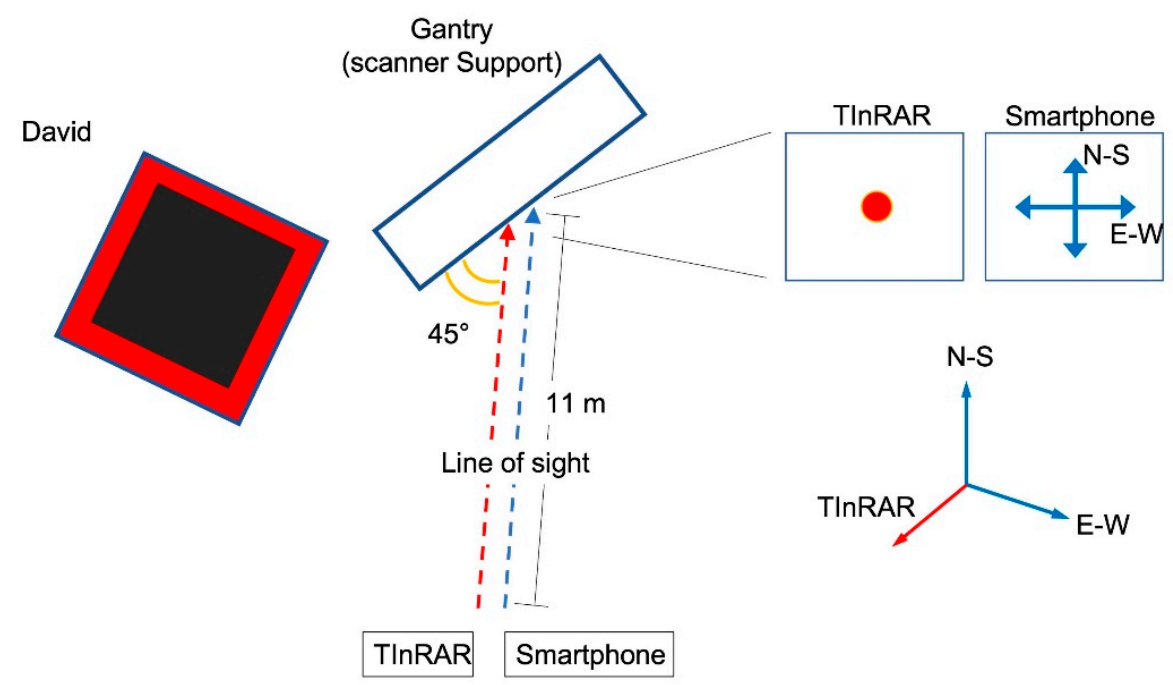

Figure 23. Geometric scheme (top-view).

\section{Conclusions}

Two different systems were used to monitor the gantry and the David statue: terrestrial TInRAR (Terrestrial Interferometric Real Aperture Radar) and PhotoMonitoring techniques. The statue demonstrated a stable behavior, while on the contrary, the gantry showed a main oscillating frequency of $1.33 \mathrm{~Hz}$. This frequency was detected by both monitoring systems, TInRAR and camera. Thanks to the TinRAR technique, the gantry and the statue were monitored with an accuracy of $0.01 \mathrm{~mm}$. Simultaneously, a Digital Image Correlation analysis was performed. Even if DIC has lower accuracy, $0.1 \mathrm{~mm}$, it accurately identifies movement directions on two axes, differently from TInRAR, which is capable of perceiving displacement in one direction only. A comparison between TinRAR and DIC results reported substantial accordance in detecting gantry's oscillating frequencies. It is worth noticing that the statue survey, made by the Structured Light Scanner, has maintained accuracy of $0.029 \mathrm{~mm}$, and a dynamic range of more than 200,000:1 [47,48]; scanning a complex and fragile surface similar to one such as David, in a sensitive and narrow space such as the exhibition museum venue, requires some ad hoc designed technical solutions, other than a highly advanced scanner.

In case studies such as this, strong stability is required. Having reliable information on the object behavior and the sensor support, in terms of oscillations and stability, allows making more effective planning and reduces pauses and downtimes.

As a general indication, performing observations in a very delicate context, as the one presented in this paper, could be considered an exception, since TInRAR and Photomonitoring are usually applied to the more common contexts, such as landslide monitoring and structural monitoring. However, the contactless characteristics give the systems a wide variety of possible applications.

Author Contributions: Conceptualization: F.M.; methodology: F.M. and P.M.; software: F.M. and A.C.; validation: F.M.; formal analysis: F.M.; investigation: F.M.; resources: F.M. and P.M.; data curation: F.M.; writing—original draft preparation: F.M.; writing—review and editing: F.M., A.C. and P.M.; visualisation: F.M.; supervision: G.T.; project administration: F.M. and G.T.; funding acquisition: G.T. and F.M. All authors have read and agreed to the published version of the manuscript.

Funding: This research received no external funding.

Institutional Review Board Statement: Not applicable.

Informed Consent Statement: Not applicable. 
Data Availability Statement: Data are available on request from the authors. The data supporting this study findings are available from the corresponding author, (Mugnai F.), upon reasonable request and are regulated by the following agreement between Galleria dell'Accademia and the Dipartimento di Ingegneria Civile e Ambientale dell'Università di Firenze: (a) Accordo di collaborazione istituzionale ex art. 15 l. N. 241/90 per la progettazione e l'esecuzione della ri-produzione del David di Michelangelo per il Padiglione Italia ad Expo 2020 Dubai e per le iniziative di valorizzazione e comunicazione ad essa connesse (Scientific Responsible for the agreement: Prof. Grazia Tucci).

Acknowledgments: The authors want to thank: (1) Ministry of Cultural Heritage and Tourism; (2) Italian Commissariat for Expo 2020 Dubai Italian General Commissioner's Office DUBAI 2020; (3) Paolo Glisenti, Commissioner General for Italy in EXPO 2020 Dubai; (4) Cecilie Hollberg, Director of the Galleria dell'Accademia di Firenze Museum in Florence (MiC-Ministry of Culture-Italy); (5) Personnel of the Galleria dell'Accademia di Firenze Museum in Florence (Italy); (6) Rosanna Binacchi, head of international relations for the General Secretariat of MiC; (7) Federica Piccirillo Art Historian of the MiC-Ministry of Culture-(Italy); (8) Saverio Romeo and Marco Baleani form NHAZCA S.r.l., for Photomonitoring and TInRAR instrumentation and acquisition campaigns. (9) Andrea Da Re for HVK Srl Consulenze metrologiche for gantry ad-hoc optimization design and implementation.

Conflicts of Interest: The authors declare no conflict of interest.

\section{References}

1. Ngeljaratan, L.; Moustafa, M.A. Structural health monitoring and seismic response assessment of bridge structures using target-tracking digital image correlation. Eng. Struct. 2020, 213, 110551. [CrossRef]

2. Brunetti, A.; Mazzanti, P. Il Monitoraggio Dinamico delle Strutture e delle Infrastrutture con Interferometria Radar Terrestre. Available online: https / / www.ingenio-web.it/ (accessed on 1 October 2019).

3. Bautista-De Castro, A.; Sánchez-Aparicio, L.J.; Ramos, L.F.; Sena-Cruz, J.; González-Aguilera, D. Integrating geomatic approaches, Operational Modal Analysis, advanced numerical and updating methods to evaluate the current safety conditions of the historical Bôco Bridge. Constr. Build. Mater. 2018, 158, 961-984. [CrossRef]

4. Civera, M.; Fragonara, L.Z.; Surace, C. Video processing techniques for the contactless investigation of large oscillations. J. Phys. Conf. Ser. 2019, 1249, 12004. [CrossRef]

5. Beninati, L.; Brunetti, A.; Caruso, C.; Mazzanti, P. Structural Health Characterization of an Old Riveted Iron Bridge by Remote Sensing Techniques. In Proceedings of the 7th International Conference on Structural Health Monitoring of Intelligent Infrastructure, Torino, Italy, 1-3 July 2015; pp. 1-3.

6. Mugnai, F. Laser Scanning and Point Cloud Segmentation for Contactless Geo-Mechanical Surveying: Conservative Restoration in Hypogeum Environment. ISPRS Int. Arch. Photogramm. Remote Sens. Spat. Inf. Sci. 2021, 46, 455-461. [CrossRef]

7. Mugnai, F.; Lombardi, L.; Tucci, G.; Nocentini, M.; Gigli, G.; Fanti, R. Geomatics in bridge structural health monitoring, integrating terrestrial laser scanning techniques and geotechnical inspections on a high value cultural heritage. In Proceedings of the International Archives of the Photogrammetry, Remote Sensing and Spatial Information Sciences, Milan, Italy, 8-10 May 2019 ; Volume 42.

8. Balageas, D.; Fritzen, C.-P.; Güemes, A. Structural Health Monitoring; John Wiley \& Sons: Hoboken, NJ, USA, 2010 ; Volume 90.

9. Castagnetti, C.; Bertacchini, E.; Capra, A.; Dubbini, M. Terrestrial laser scanning for preserving cultural heritage: Analysis of geometric anomalies for ancient structures. In Proceedings of the FIG Working Week 2012-Territory, Environment, and Cultural Heritage, Rome, Italy, 6-10 May 2012; pp. 1-13.

10. Achille, C.; Adami, A.; Chiarini, S.; Cremonesi, S.; Fassi, F.; Fregonese, L.; Taffurelli, L. UAV-based photogrammetry and integrated technologies for architectural applications-Methodological strategies for the after-quake survey of vertical structures in Mantua (Italy). Sensors 2015, 15, 15520-15539. [CrossRef] [PubMed]

11. Fregonese, L.; Barbieri, G.; Biolzi, L.; Bocciarelli, M.; Frigeri, A.; Taffurelli, L. Surveying and monitoring for vulnerability assessment of an ancient building. Sensors 2013, 13, 9747-9773. [CrossRef]

12. Mazzanti, P.; Bozzano, F.; Brunetti, A.; Esposito, C.; Martino, S.; Prestininzi, A.; Rocca, A.; Mugnozza, G.S. Terrestrial SAR interferometry monitoring of natural slopes and man-made structures. In Engineering Geology for Society and Territory; Springer: Berlin/Heidelberg, Germany, 2015; Volume 5, pp. 189-194.

13. Bernardini, G.; De Pasquale, G.; Gallino, N.; Gentile, C. Microwave interferometer for ambient vibration measurements on civil engineering structures: 2. Application to full-scale Bridges. In Proceedings of the Experimental Vibration Analysis for Civil Engineering Structures (EVACES’07), Porto, Portugal, 24-26 October 2007; pp. 153-162.

14. Hanssen, R.F. Radar Interferometry: Data Interpretation and Error Analysis; Springer Science \& Business Media: New York, NY, USA, 2001; Volume 2.

15. Qing, X.P.; Beard, S.J.; Kumar, A.; Ooi, T.K.; Chang, F.-K. Built-in sensor network for structural health monitoring of composite structure. J. Intell. Mater. Syst. Struct. 2007, 18, 39-49. [CrossRef] 
16. Bongiovanni, G.; Brunetti, A.; Clemente, P.; Conti, C.; Mazzanti, P.; Verrubbi, V. Dynamic characterization of tower structures by means of interferometry measurements. In Proceedings of the 7th International Conference on Structural Health Monitoring of Intelligent Infrastructure, Torino, Italy, 1-3 July 2015; pp. 1-3.

17. Gracchi, T.; Lotti, A.; Saccorotti, G.; Lombardi, L.; Nocentini, M.; Mugnai, F.; Gigli, G.; Barla, M.; Giorgetti, A.; Antolini, F. A method for locating rockfall impacts using signals recorded by a microseismic network. Geoenviron. Disasters $2017,4,26$. [CrossRef]

18. Schumacher, T.; Shariati, A. Monitoring of Structures and Mechanical Systems Using Virtual Visual Sensors for Video Analysis: Fundamental Concept and Proof of Feasibility. Sensors 2013, 13, 16551-16564. [CrossRef]

19. Chopra, A.K. Dynamics of Structures; Pearson Education: Sholinganallur, Chennai, India, 2007.

20. Bickel, V.T.; Manconi, A.; Amann, F. Quantitative assessment of digital image correlation methods to detect and monitor surface displacements of large slope instabilities. Remote Sens. 2018, 10, 865. [CrossRef]

21. Antonielli, B.; Caporossi, P.; Mazzanti, P.; Moretto, S.; Rocca, A. InSAR \& Photomonitoringtm for Dams and Reservoir Slopes Health \& Safety Monitoring. In Proceedings of the Twenty-Sixth International Congress on Large Dams/Vingt-Sixième Congrès International des Grands Barrages, Vienna, Austria, 4-6 July 2018; p. 4.

22. Mugnai, F.; Tucci, G.; Da Re, A. Digital image correlation in assessing structured-light 3D scanner's gantry stability: Performing david's (michelangelo) high-accuracy 3D survey. In Proceedings of the International Archives of the Photogrammetry, Remote Sensing and Spatial Information Sciences, Torino, Italy, 1 August 2021; Volume XLVI-M-1-2, pp. 463-469. [CrossRef]

23. Bing, P.; Hui-Min, X.; Bo-Qin, X.; Fu-Long, D. Performance of sub-pixel registration algorithms in digital image correlation. Meas. Sci. Technol. 2006, 17, 1615. [CrossRef]

24. Pan, B.; Qian, K.; Xie, H.; Asundi, A. Two-dimensional digital image correlation for in-plane displacement and strain measurement: A review. Meas. Sci. Technol. 2009, 20, 62001. [CrossRef]

25. Wen, D.; Huang, X.; Bovolo, F.; Li, J.; Ke, X.; Zhang, A.; Benediktsson, J.A. Change Detection From Very-High-Spatial-Resolution Optical Remote Sensing Images: Methods, applications, and future directions. IEEE Geosci. Remote Sens. Mag. 2021, 2-35. [CrossRef]

26. Yu, L.; Pan, B. In-plane displacement and strain measurements using a camera phone and digital image correlation. Opt. Eng. 2014, 53, 54107. [CrossRef]

27. Patsias, S.; Staszewskiy, W.J. Damage Detection Using Optical Measurements and Wavelets. Struct. Health Monit. 2002, 1, 5-22. [CrossRef]

28. Fu, G.; Moosa, A.G. An optical approach to structural displacement measurement and its application. J. Eng. Mech. 2002, 128, 511-520. [CrossRef]

29. Baqersad, J.; Poozesh, P.; Niezrecki, C.; Avitabile, P. Photogrammetry and optical methods in structural dynamics-A review. Mech. Syst. Signal Process. 2017, 86, 17-34. [CrossRef]

30. Feng, D.; Feng, M.Q. Experimental validation of cost-effective vision-based structural health monitoring. Mech. Syst. Signal Process. 2017, 88, 199-211. [CrossRef]

31. Mazzanti, P.; Caporossi, P.; Muzi, R. Sliding Time Master Digital Image Correlation Analyses of CubeSat Images for landslide Monitoring: The Rattlesnake Hills Landslide (USA). Remote Sens. 2020, 12, 592. [CrossRef]

32. Fastellini, G.; Grassi, S.; Marrucci, M.; Radicioni, F. Michelangelo's David: Historical images for the preservation of a masterpiece. In Proceedings of the CIPA 2005 XX International Symposium, Torino, Italy, 27 September-1 October 2005.

33. Levoy, M.; Pulli, K.; Curless, B.; Rusinkiewicz, S.; Koller, D.; Pereira, L.; Ginzton, M.; Anderson, S.; Davis, J.; Ginsberg, J. The digital Michelangelo project: 3D scanning of large statues. In Proceedings of the 27th Annual Conference on Computer Graphics and Interactive Techniques, New York, NY, USA, 1 July 2000; pp. 131-144.

34. Rugis, J. Surface curvature maps and Michelangelo's David. In Image and Vision Computing New Zealand; University of Auckland: Auckland, New Zealand, 2005; Volume 2005, pp. 218-222.

35. Koller, D.; Turitzin, M.; Levoy, M.; Tarini, M.; Croccia, G.; Cignoni, P.; Scopigno, R. Protected interactive 3D graphics via remote rendering. ACM Trans. Graph. 2004, 23, 695-703. [CrossRef]

36. Brown, B.J.; Rusinkiewicz, S. Non-rigid range-scan alignment using thin-plate splines. In Proceedings of the 2nd International Symposium on 3D Data Processing, Visualization and Transmission, Washington, DC, USA, 6-9 September 2004; pp. 759-765.

37. Bernardini, F.; Rushmeier, H.; Martin, I.M.; Mittleman, J.; Taubin, G. Building a digital model of Michelangelo's Florentine Pieta. IEEE Comput. Graph. Appl. 2002, 22, 59-67. [CrossRef]

38. Gonzalez-Drigo, R.; Cabrera, E.; Luzi, G.; Pujades, L.G.; Vargas-Alzate, Y.F.; Avila-Haro, J. Assessment of post-earthquake damaged building with interferometric real aperture radar. Remote Sens. 2019, 11, 2830. [CrossRef]

39. Negulescu, C.; Luzi, G.; Crosetto, M.; Raucoules, D.; Roullé, A.; Monfort, D.; Pujades, L.; Colas, B.; Dewez, T. Comparison of seismometer and radar measurements for the modal identification of civil engineering structures. Eng. Struct. 2013, 51, 10-22. [CrossRef]

40. Luzi, G.; Crosetto, M.; Cuevas-González, M. A radar-based monitoring of the Collserola tower (Barcelona). Mech. Syst. Signal Process. 2014, 49, 234-248. [CrossRef]

41. Ekstrom, M.P. Digital Image Processing Techniques; Academic Press: Cambridge, MA, USA, 2012; Volume 2.

42. Caporossi, P.; Mazzanti, P.; Bozzano, F. Digital image correlation (DIC) analysis of the 3 December 2013 Montescaglioso landslide (Basilicata, southern Italy): Results from a multi-dataset investigation. ISPRS Int. J. Geo-Inf. 2018, 7, 372. [CrossRef] 
43. Stumpf, A. Landslide Recognition and Monitoring with Remotely Sensed Data from Passive Optical Sensors. Ph.D. Thesis, University of Strasbourg, Strasbourg, France, 2013.

44. Tong, X.; Luan, K.; Stilla, U.; Ye, Z.; Xu, Y.; Gao, S.; Xie, H.; Du, Q.; Liu, S.; Xu, X.; et al. Image Registration with Fourier-Based Image Correlation: A Comprehensive Review of Developments and Applications. IEEE J. Sel. Top. Appl. Earth Obs. Remote Sens. 2019, 12, 4062-4081. [CrossRef]

45. XIAOMI REDMI NOTE 8T Technical Specs. 2021. Available online: https://www.mi.com/it/redmi-note-8-t/specs/ (accessed on 10 October 2021).

46. Luzi, G.; Crosetto, M.; Fernández, E. Radar interferometry for monitoring the vibration characteristics of buildings and civil structures: Recent case studies in Spain. Sensors 2017, 17, 669. [CrossRef] [PubMed]

47. Feng, S.; Zhang, L.; Zuo, C.; Tao, T.; Chen, Q.; Gu, G. High dynamic range 3d measurements with fringe projection profilometry: A review. Meas. Sci. Technol. 2018, 29, 122001. [CrossRef]

48. Scott, R.P.; Langrock, C.; Kolner, B.H. High-dynamic-range laser amplitude and phase noise measurement techniques. IEEE J. Sel. Top. Quantum Electron. 2001, 7, 641-655. [CrossRef] 